\title{
Налоговое право
}

\section{Правовое регулирование медиации как альтернативного способа разрешения спора: налогово-правовой аспект}

\begin{abstract}
Аннотация. В Российской Федерации медиация как альтернативный способ разрешения спора стала официально применяться с появлением в 2010 2. отдельного нормативного акта. Начиная с 2019 г. медиация применяется в публичных правоотношениях. В конце 2020 2. был зафиксирован первый случай проведения процедуры медиации в налоговой сфере. В рамках настоящей публикации авторы анализируют действующее положение медиации, и в частности налоговой медиации, и высказывают свои предложения в вопросах популяризации и применения медиативных процедур при разрешении споров.

Ключевые слова: медиация, налоговая медиация, альтернативные способы разрешения спора, медиатор.
\end{abstract}

\section{DOI: 10.17803/2311-5998.2021.85.9.089-097}

L. L. ARZUMANOVA,

Professor of Department in financial law of Kutafin Moscow State Law University (MSAL), Dr. Sci. (Law), Associate professor Ilarzumanova@yandex.ru 9, ul. Sadovaya-Kudrinskaya, Moscow, Russia, 125993

A. A. GRIGOR'EV, Director of the Department "Taxes. Technologies. Dispute resolution" FBK «Legal», mediator grigorieva@fbk.ru 48, ul. Myasnickaya, Moscow, Russia, 107078

\section{Legal regulation of mediation as an alternative method of dispute resolution: legal tax aspect}

\begin{abstract}
In the Russian Federation, mediation as an alternative method of dispute resolution was officially applied with the introduction of a separate regulatory act in 2010. Starting in 2019, mediation is used in public legal relations. At the end of 2020, the first case of mediation in the tax sphere was recorded. Within the framework of this publication, the authors analyze the current situation of mediation and, in particular, tax mediation, and express their proposals on the popularization and application of mediation procedures in dispute resolution. Keywords: mediation, tax mediation, alternative dispute resolution methods, mediator.
\end{abstract}

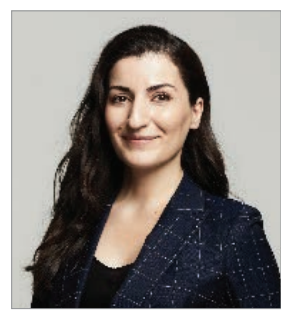

Лана Львовна АРЗУМАНОВА, профрессор кафредры финансового права Университета имени О.Е. Кутафиина (МГЮА), доктор юридических наук, дочент llarzumanova@msal.ru 125993, Россия, г. Москва, ул. Садовая-Кудринская, д. 9

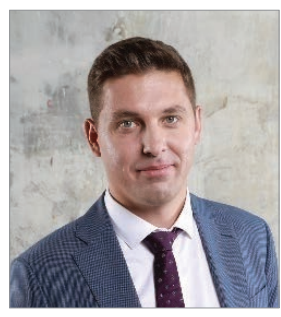

\section{Александр} Александрович ГРИГОРЬЕВ, директор Департамента «Налоги. Технологии. Урегулирование споров» ФБК «Legal», мeдuamop grigorieva@fbk.ru 107078, Россия, г. Москва, ул. Мясницкая, д. 48

(С) Л. Л. Арзуманова, А. А. Григорьев, 2021 


\section{Введение}

В целях создания нормативных предпосылок применения на территории нашего государства такой альтернативной процедуры урегулирования споров, как медиация, в 2010 г. был принят Федеральный закон «Об альтернативной процедуре урегулирования споров с участием посредника (процедуре медиации)» (далее - Закон о процедуре медиации) ${ }^{1}$, который ориентирует общество на развитие партнерских деловых отношений, формирование этики делового оборота и в целом - гармонизацию социальных отношений.

На сегодняшний день в Законе о процедуре медиации отсутствует фрундаментальная дефиниция, однако, анализируя нормы правового акта, можно вывести определение медиации - альтернативного способа разрешения спора при участии беспристрастного, нейтрального и независимого лица - медиатора, содействующего сторонам спора в поиске, выработке и принятии взаимоприемлемого и жизнеспособного решения, отражающего интересы и потребности сторон.

При этом следует отметить, что процедура медиации в России неприменима к коллективным трудовым спорам, а также к конфликтам, затрагивающим права и законные интересы третьих лиц, не участвующих непосредственно в процедуре, или публичные интересы.

Необходимо подчеркнуть, что медиация применительно к административным и публичным правоотношениям стала возможной благодаря изменениям, внесенным в действующий Закон о процедуре медиации Федеральным законом от 26 июля 2019 г. № $197-Ф 3^{2}$.

С учетом появившейся нормы особую актуальность приобретает вопрос о том, как выстраивать переговорный процесс с органами государственной власти и какова готовность публичных органов власти вступать в медиацию и принимать на паритетных началах решения, которые могут удовлетворить интересы каждой из сторон.

Отчасти такая логика усложняется тем обстоятельством, что для сторон, особенно обремененных государственным элементом, является привычной потребность в решении, в котором суд как независимый орган власти поддерживает или отказывает стороне в заявленных требованиях. Выработанный таким образом подход позволяет в наименьшей степени сомневаться в решении, даже несмотря на не всегда положительный исход самого дела для стороны.

Однако в этой, казалось бы, традиционной траектории отсутствует важный фрактор - исполнимость решения. Отчасти это можно обосновать как отсутствием добровольного подхода к принятию решения, так и опосредованным участием сторон процесса в фрормировании резолютивной части решения, из которой следует, как и в какой ситуации должна действовать сторона процесса.

1 Федеральный закон от 27 июля 2010 г. № 193-Ф3 «Об альтернативной процедуре урегулирования споров с участием посредника (процедуре медиации)» // СЗ РФ. 2010. № 31. Ст. 4162.

2 Федеральный закон от 26 июля 2019 г. № 197-Ф3 «О внесении изменений в отдельные законодательные акты Российской Федерации» // С3 РФ. 2019. № 30. Ст. 4099. 


\begin{tabular}{|c|c|}
\hline 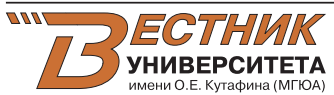 & $\begin{array}{l}\text { Арзуманова Л. Л., Григорьев А. А. } \\
\text { Правовое регулирование медиации как альтернативного } \\
\text { способа разрешения спора: налогово-правовой аспекТ }\end{array}$ \\
\hline
\end{tabular}

В то же время именно благодаря медиативному подходу, основанному на принципах добровольности, конфиденциальности, сотрудничества и равноправия сторон, беспристрастности и независимости медиатора, а также конфиденциальности всей процедуры медиации, по-настоящему возможен результат «на исполнение», о чем свидетельствуют российские и зарубежные практики. К сожалению, суд не может обеспечить исполнимость решения, поскольку отсутствует консенсус между сторонами в момент принятия решения, за исключением случаев заключения мировых соглашений, в которых тем не менее не всегда проясняются истинные намерения сторон, а судом проверяется лишь соответствие их поведения нормативным правовым актам.

С учетом обозначенной проблематики и новизны научного интереса в отношении споров, вытекающих из публично-правовых отношений, предлагается остановиться на изучении возможности использования процедуры медиативных сессий применительно к налоговой сфере и ее перспектив.

Прежде чем перейти к анализу норм и представить свое ви́дение процесса, отметим, что в ноябре 2020 г. руководитель Управления ФНС России по СанктПетербургу, отмечая в целом положительную динамику качества проводимых налоговых проверок, анонсировал первый опыт «построения новой системы взаимоотношений между налоговыми органами и представителями бизнеса» ${ }^{3}$, участие в котором позволило заключить медиативное соглашение между налоговым органом и налогоплательщиком.

В последующем в рамках серии научно-практических мероприятий, в том числе Петербургского международного юридического фрорума, стали обсуждаться вопросы возможного применения медиации в области налогообложения, был представлен зарубежный опыт такого вида медиации, а также услышана позиция ФНС России по данному вопросу, которая в целом не отвергает возможность имплементирования медиации к сфере налоговых правоотношений, однако считает, что прежде всего этому должно предшествовать изучение в том числе практики применения процедуры нашими иностранными партнерами, у которых уже накопился опыт использования медиативных технологий на судебной и досудебной стадиях.

С учетом изложенного выше и обозначения реперных точек, предлагается перейти к анализу правового содержания налоговой медиации как специального ее вида.

\section{К вопросу о нормативно-правовом регулировании налоговой медиации}

Существующее законодательное поле позволяет сделать вывод о том, что налоговые органы действуют в пределах полномочий, которые закреплены в Налоговом кодексе Р $\Phi^{4}$.

\footnotetext{
3 Медиация - новое слово в налоговом контроле // URL: https://www.nalog.gov.ru/rn78/ news/activities fts/10194093/.

4 СЗ РФ. 1998. № 31. Ст. 3824.
} 
При этом пределы применения процедуры медиации продиктованы невозможностью изменения сторонами налогово-правовых последствий и публичных обязанностей сторон, установленных императивными нормами законодательства о налогах и сборах. Тем не менее положительный эксперимент применения медиации, о котором речь шла выше, в том числе больший чем в России зарубежный опыт, демонстрирует эфрфективность применения настоящей процедуры в вопросах прояснения сторонами своих истинных интересов и фактических обстоятельств в рамках отношений, которые возникают между ними и, как следствие, порождают соответствующие последствия, включая возможность сближения ими своих позиций.

Поскольку процедура медиации представляет собой альтернативный способ разрешения спора при участии беспристрастного, нейтрального и независимого лица - медиатора, содействующего сторонам спора в поиске, выработке и принятии взаимоприемлемого, жизнеспособного и, главное, исполнимого решения, отражающего интересы и потребности обеих сторон, участники в таком процессе ориентированы на открытость и непосредственное разрешение конфликта.

При этом, как отмечалось выше, процедура медиации отличается прозрачностью. В подробном вступительном слове медиатор излагает порядок проведения и принципы процедуры медиации, обозначая, что окончательные договоренности сторон вырабатываются в ходе проведения медиативных сессий и подробно излагаются в медиативном соглашении, подписываемым сторонами после его окончательной сверки.

В этой связи представляется возможным подчеркнуть, что, в отличие от судебного разбирательства, как и традиционного досудебного обжалования налогового спора, в ходе процедуры альтернативного разрешения спора - медиации решение принимается исключительно самими сторонами спора по взаимному согласию. Медиатор не только не обладает полномочиями по принятию каких-либо решений, но и не вправе давать рекомендации сторонам по существу самого спора, придерживаясь принципа нейтральности. В противном случае это будет признано нарушением процедуры, а медиатор, утратив доверие стороны, может создать еще бо́льший конфликт и породить отрицательное отношение к процедуре в целом. В этом смысле вся полнота полномочий по принятию решений в процедуре медиации должна оставаться за сторонами спора в налоговых правоотношениях, т.е. исключительно за налоговым органом и налогоплательщиком.

В настоящее время практика исходит из того, что посредством участия в процедуре медиации при соблюдении ее принципов налоговые органы реализуют свои права, в том числе предусмотренные пп. 4 и 8 п. 1 ст. 31 НК РФ, согласно которым налоговый орган вправе вызывать на основании письменного уведомления в налоговые органы налогоплательщиков для дачи пояснений в связи с уплатой (удержанием и перечислением) ими налогов и сборов либо в связи с налоговой проверкой, а также в иных случаях, связанных с исполнением ими законодательства о налогах и сборах, а также требовать от налогоплательщиков, плательщиков сборов, налоговых агентов, их представителей устранения выявленных нарушений законодательства о налогах и сборах и контролировать выполнение указанных требований.

С другой стороны, процедура медиации может рассматриваться и как один из способов реализации налогоплательщиками своих прав, закрепленных п. 1 


\begin{tabular}{|c|c|}
\hline 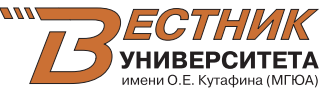 & $\begin{array}{l}\text { Арзуманова Л. Л., Григорьев А. А. } \\
\text { Правовое регулирование медиации как альтернативного } \\
\text { способа разрешения спора: налогово-правовой аспект }\end{array}$ \\
\hline
\end{tabular}

ст. 21 НК РФ, в частности права на получение по месту своего учета от налоговых органов бесплатной информации о действующих налогах и сборах, законодательстве о налогах и сборах и принятых в соответствии с ним нормативных правовых актах, порядке исчисления и уплаты налогов и сборов, правах и обязанностях налогоплательщиков, полномочиях налоговых органов и их должностных лиц, а также права на представление налоговым органам и их должностным лицам пояснений по исчислению и уплате налогов.

В силу пункта 1 ст. 22 НК РФ порядок защиты прав и законных интересов налогоплательщиков (плательщиков сборов, плательщиков страховых взносов) определяется Кодексом и иными фредеральными законами.

Правовые условия применения медиации к отношениям, возникающим из административных и иных публичных правоотношений, установлены в Законе о процедуре медиации. Из этого следует, что в ходе участия в процедуре медиации должностные лица налоговых органов могут руководствоваться НК РФ, Законом о процедуре медиации и другими нормативными правовыми актами, включая методические документы ФНС России.

Таким образом, в настоящее время явного противоречия для применения процедуры медиации к налоговым правоотношениям не усматривается.

В то же время авторы публикации не отрицают необходимость изучения зарубежного опыта с учетом поэтапного освоения позитивных практик, российских пилотных проектов и публичного обсуждения позиций налогового органа совместно с научным и практикующим сообществом, а также медиаторами. В этой связи в мае 2021 г. было принято решение на базе Университета имени О.Е. Кутафина (МГЮА) создать рабочую группу — площадку, где будут обсуждаться эти и более частные вопросы: кто может быть медиатором в таком процессе, какие споры могут быть признаны медиабельными и др.

\section{Попытки популяризировать процедуру медиации в налогово-правовой сфере}

Как представляется, для более массового распространения института медиации было бы полезно закрепить права участников налоговых правоотношений на обращение к процедуре медиации, несмотря на то, что в настоящее время прямого запрета к ее использованию не имеется. Такой подход придаст процедуре более официальный характер и упрочит позицию налоговой структуры (сделает ее более обоснованной) в случае ее применения.

Также требуют обсуждения вопрос закрепления правового статуса медиатора непосредственно в НК РФ и те процессуальные рамки, в которых медиатор мог бы быть официально приглашен сторонами в целях оказания помощи в урегулировании разногласий. Такое регулирование могло бы стать несомненным плюсом хотя бы для понимания того, что такой институт существует и применяется в налоговых правоотношениях, а также способствовало бы более «спокойному» обращению к ней фрискального органа.

Представляется возможным предложить наряду с порядком обжалования актов налоговых органов и действий или бездействия их должностных лиц, установленных 
в гл. 19 НК РФ, предусмотреть порядок обращения к процедуре налоговой медиации, тем более что право обращения к такой процедуре и ее применение прямо отражены в Законе о процедуре медиации, в частности в его ч. 1 ст. 1.

Также следует учесть, что изменение, внесенное законодателем в ч. 2 ст. 1 рассматриваемого Закона (о возможности применения процедуры медиации к спорам, возникающим из административных и публичных правоотношений), имело своей целью буквальное установление применимости медиации к публичным правоотношениям. При этом ч. 5 ст. 1 Закона о процедуре медиации как в первой, так и в последующих редакциях определяет, что процедура медиации не применяется к коллективным трудовым спорам, а также спорам, возникающим из отношений, указанных в ч. 2 данной статьи, в случае, если такие споры затрагивают или могут затронуть права и законные интересы третьих лиц, не участвующих в процедуре медиации, или публичные интересы.

По нашему мнению, что такая норма направлена именно на исключение ситуаций, когда решение по спору было бы принято сторонами, которые не наделены полнотой полномочий по его принятию, либо когда принятие жизнеспособного решения, удовлетворяющего интересам всех сторон, представляется затруднительным в связи с множественностью участников спора и потенциальным нарушением законных интересов третьих лиц, не участвующих в процедуре медиации.

Отметим, что налоговые органы Российской Федерации, представляя собой единую централизованную систему контроля за соблюдением законодательства о налогах и сборах, за правильностью исчисления, полнотой и своевременностью уплаты (перечисления) в бюджетную систему Российской Федерации налогов, сборов, страховых взносов, напротив, законодательно наделены соответствующими полномочиями по защите публичных интересов, вытекающих из налоговых правоотношений, и вправе принимать обязывающие налогоплательщика решения в рамках полномочий, предоставленных им НК РФ.

Такие полномочия налоговой службы позволяют в случае участия в процедуре медиации налогового органа, в котором на учете состоит налогоплательщик сторона спора, исключить возможность принятия решения неуполномоченными сторонами и признания спора немедиабельным в силу ч. 5 ст. 1 Закона о процедуре медиации. В противном случае следовал бы вывод о буквальном противоречии между ч. 2 и 5 ст. 1 Закона о процедуре медиации относительно вопроса применимости медиации к спорам, возникающим из публичных правоотношений.

Важно подчеркнуть, что изменение, внесенное законодателем в ч. 2 ст. 1 Закона о процедуре медиации, имело своей целью буквальное установление применимости медиации к публичным правоотношениям.

В этой связи баланс частных и публичных интересов в налоговых правоотношениях обеспечивается за счет формальной определенности норм законодательства о налогах и сборах, в том числе устанавливающих обязательные элементы налогообложения. В этом смысле предметом спора и медиативного (мирового) соглашения не должны выступать установленные законом налогово-правовые последствия, вытекающие из фрактических обстоятельств.

Другим словами, налоговые органы и налогоплательщики не вправе инициировать и рассматривать спор, к примеру, относительно величины ставок налога, видов объектов налогообложения, порядка определения налоговой базы, 
поскольку такой спор касался бы изменения установленной законом обязанности, а следовательно, затрагивал бы публичные интересы.

Здесь можно оговориться, что такой «метод исключения» широко используется в зарубежной законодательной практике проведения налоговых медиаций, когда на уровне закона перечислены случаи, при которых медиация невозможна. Этот подход вполне оправдан, поскольку, с одной стороны, защищает интересы общества и государства и не позволяет расширительно толковать применение процедуры, а с другой - отношения в эпоху цифровизации расширяются и появляется все большее количество объектов налогообложения, в связи с чем такой подход позволит избежать «ежедневного ручного» изменения законодательства.

Между тем медиация может применяться и в тех случаях, когда:

- нарушена коммуникация между налогоплательщиком и налоговым органом;

- имеется спор о фрактических обстоятельствах;

- спор представляется результатом недопонимания сторонами друг друга;

- налогоплательщик не уверен, какая информация была исследована налоговым органом;

- налоговый орган планирует объяснить, по какой причине требуется больше информации от налогоплательщика.

То есть в целом такая медиация не всегда должна заканчиваться подписанием медиативного соглашения, а возможно выстраивание взаимопонимания между участниками, когда они были услышаны друг другом и готовы двигаться по определенной дорожной карте, с тем чтобы урегулировать спор и, возможно, принять или признать позицию стороны.

В то же время в медиативном соглашении стороны могут прийти к согласованию обстоятельств спора, от которых зависит возникновение соответствующих налоговых последствий и правовая квалификация деятельности налогоплательщика, а также условий, при которых возможно достижение соглашения по обстоятельствам спора (например, представление налогоплательщиком определенных документов (информации), подтверждающих расходы и налоговые вычеты).

В зависимости от обстоятельств в медиативном соглашении может быть дана квалификация действиям налогоплательщика и определены соответствующие правовые последствия таких действий в соответствии с законодательством о налогах и сборах, а также установлен порядок исполнения обязательств по медиативному соглашению.

Предлагаемые выводы согласуются в том числе и с правовой позицией постановления Пленума Высшего Арбитражного Суда РФ от 18 июля 2014 г. № 50 «О примирении сторон в арбитражном процессе» ${ }^{5}$ по вопросу заключения мировых соглашений по налоговым спорам (п. 27 постановления).

\section{Лучшие зарубежные практики}

Одной из стран, где «процветает» медиация в разных областях, является Австралия, в которой признается принцип доступа к правосудию, означающий развитие как судебного, так и внесудебного способа урегулирования споров. По заявлению

5 Вестник экономического правосудия Российской Федерации. 2014. № 9.

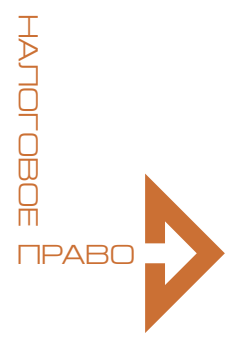


судьи федерального суда Австралии Гринвуда, «для разрешения многих судебных дел не было необходимости судебного вмешательства». Именно на таком фундаментальном тезисе и построена система правосудия страны, которая подталкивает стороны к безконфликтному разрешению спора и лишь в крайнем случае - к обращению в судебные инстанции.

В некоторых юрисдикциях медиабельность налогового спора определяется исходя из обратного принципа, а именно в ситуациях, при возникновении которых решение о проведении переговорного процесса не будет принято. Среди таких случаев можно назвать следующие:

- имеется прецедентное решение по аналогичной категории спора;

- расходы и издержки несоразмерны возможной выгоде;

- спорные вопросы касаются основополагающих принципов налогообложения или имеется общественная целесообразность принятия судебного решения;

- обстоятельства дела очевидны;

- представлены обоснованные подозрения о мошеннических действиях или злонамеренном уклонении от уплаты налогов.

Аналогичная практика исключения из общего правила применяется и в США, где медиация насчитывает десятилетия, а активная фаза ее становления начинается с 1970-х гг. Так, например, в США налоговая медиация возможна при наличии следующего условия - отсутствуют признаки уголовно-наказуемого уклонения от уплаты налогов.

По высказываниям О. Фолберга, «правительство использует медиацию, чтобы стороны могли договориться в случае, если возникают разногласия относительно суммы налогов на основе расхождения взглядов на фактическую информацию или на толкование налогового законодательства» ${ }^{6}$.

Важно подчеркнуть, что практика применения медиации в налоговых правоотношениях абсолютно разная. К примеру, в рамках эксперимента в Нидерландах на медиацию было передано 75 споров, из них 80 \% окончены подписанием медиативного соглашения, остальные рассмотрены в последующем в судебном порядке. Опыт же Индии свидетельствует об обратном: была предпринята попытка разрешить посредством медиации 38 кейсов и лишь 4 из них стали успешными. Тем не менее такое положение дел не изменило в целом позитивный настрой государства к применению процедуры и она стала применяться в разных сферах правового регулирования, в том числе в качестве обязательной досудебной стадии.

\section{Выводы}

Основные предложения по развитию практики применения налоговой медиации были представлены по всему тексту работы. Безусловен тот факт, что для более глубоких выводов и предложений в первую очередь необходимо расширять практику, чтобы понять, к каким именно спорам и случаям применима медиация

6 Цит. по: Шередеко Е. В. Медиация в налоговом споре: опыт зарубежных стран // Финансовое право. 2012. № 8. С. 39-40. 
в нашей стране в области налогообложения.

Однако представляется возможным уже сейчас выявить общие тренды, которые сводятся к следующим положениям:

1. Наблюдается явный интерес к развитию медиации в сфере, где одним из субъектов является государство в лице того или иного органа власти.

2. Налоговая медиация не представляет собой распространенный институт, несмотря на существующие практики.

3. Налоговая медиация существенным образом отличается от других видов медиации по некоторым критериям:

- субъектному составу;

- ограниченному кругу вопросов для разрешения спора, что отчасти оправдывается четкой урегулированностью большинства налоговых процессов.

Однако важно понимать, что в основе спора между налоговым органом и налогоплательщиком всегда лежит баланс публичных и частных интересов. В этой связи задача государства сводится к пополнению бюджета страны и одновременно созданию условий сохранения налогоплательщика и его последующего экономического развития.

В свою очередь, для налогоплательщика важна определенность в налоговых правоотношениях, которая ввиду сложности налогового регулирования и постоянно меняющихся условий налогообложения далеко не всегда возможна без открытого диалога между властью и бизнесом. Именно выстраивание культуры такого общения, в том числе с привлечением профессионалов в сфере межличностных коммуникаций, может стать основой для уверенного развития экономики и бизнеса.

В заключение отметим, что работу по изучению медиации и ее практическому применению следует проводить и в дальнейшем, выявляя тем самым реальные интересы налогового органа и налогоплательщика в целях разрешения конфликтов и установления здоровых партнерских отношений.

\section{БИБЛИОГРАФИЯ}

1. Медиация - новое слово в налоговом контроле // URL: https://www.nalog.gov. ru/rn78/news/activities_fts/10194093/.

2. Шередеко Е. В. Медиация в налоговом споре: опыт зарубежных стран // Финансовое право. — 2012. — № 8. - С. 39-40. 